\title{
Повышение безопасности и надежности умных замков
}

\author{
А. Ухов, д. т.н. ${ }^{1}$, В. Герасимов ${ }^{2}$, Л. Селиванов ${ }^{3}$, В. Симон ${ }^{4}$
}

УДК 683.336:621.396 | ВАК 05.27.01

"Умными" принято называть технологии повышения жизненного комфорта. Такие технологии входят практически во все сферы жизни, и умный замок (также известен как смарт-замок или smart lock) является хорошим примером подобных устройств. Рынок умных замков сегодня быстро растет. В статье рассмотрена новая конструкция умного замка с двумя каналами связи, рассчитано его энергопотребление и обосновано преимущество использования дополнительного канала связи для повышения безопасности и надежности замка.

P азрабатывая любое сложное потребительское устройство, в первую очередь необходимо понимать, что требуется конечному потребителю. Масштабные исследования показали, что большинство потребителей считают самым главным для умных замков безопасность, а уже затем простоту использования. Сохранность имущества, а, возможно, и личная безопасность зависят от качества и надежности замка. Периодически появляющиеся сообщения о "взломе» смарт-устройств приводят к тому, что потенциальные потребители отказываются приобретать такие устройства из-за их недостаточной безопасности. Поэтому для расширения рынка необходимо повысить надежность и безопасность умных замков, поскольку потребители будут доверять только таким устройствам.

На отечественном рынке в настоящее время представлены умные замки исключительно иностранного производства, что приводит к увеличению их стоимости и ограничивает возможности по их обслуживанию. Кроме того, подобные изделия не могут быть интегрированы в отечественные охранные системы, либо такая интеграция будет иметь существенные

Федеральное государственное автономное образовательное учреждение высшего образования "Санкт-Петербургский государственный электротехнический университет "лэтИ" им. В.И. Ульянова (Ленина)» (СПбгЭТУ «ЛЭТИ»), профессор, aauhov@yandex.ru

спбгЭТу «лЭТИ», ассистент,

vl.gerasimov@mail.ru.

спбгЭту «лЭТИ», ассистент,

Imselivanov@gmail.com.

спбгЭТу «ЛЭТИ», аспирант,

vsev.simon@gmail.com. ограничения. Для решения данных проблем научнотехническая и коммерческая фирма “Си-Норд" совместно с Санкт-Петербургским государственным электротехническим университетом "лэтИ» им. В.И. Ульянова (Ленина) в рамках проекта «Автоматизированная система интеллектуальной защиты жилой, коммерческой и общественной недвижимости с использованием облачных вычислений» разработала умный замок (рис. 1), имеющий ряд преимуществ по сравнению с зарубежными аналогами:

- существенно более простая кинематика управления основным дверным замком, что позволяет снизить стоимость изделия;

- наличие дополнительного канала связи между умным замком и пультом охраны.

\section{КОНСТРУКЦИЯ УМНОГО ЗАМКА}

Практически все умные замки - это беспроводные устройства с батарейным питанием. Базовая структура умного замка показана на рис. 2.
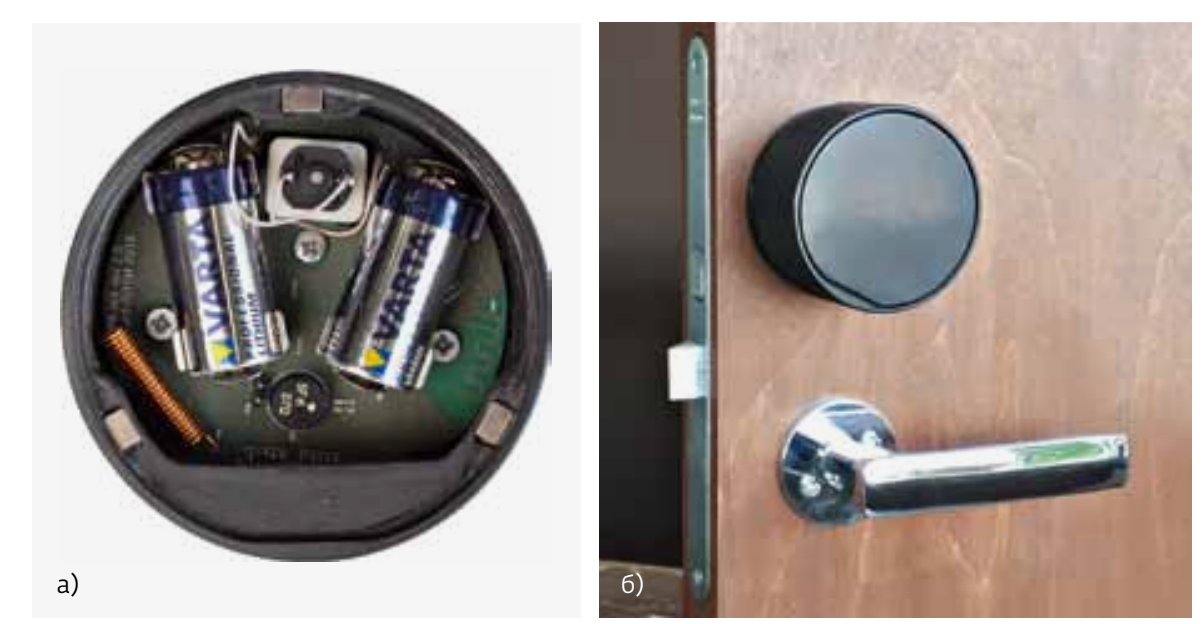

Рис. 1. Умный замок со снятой верхней крышкой (а) и установленный на дверь (б) 
Беспроводная связь позволяет пользователю не только дистанционно открывать и закрывать замок, но и получать информацию о его текущем состоянии и истории работы. С другой стороны, умные замки расположены внутри квартиры, и беспроводная связь - это единственный способ для их «взлома».

Большинство популярных умных замков имеют интерфейс связи Bluetooth для прямого управления с помощью смартфона [1]. Для каналов беспроводной связи Bluetooth и Bluetooth Low Energy (BLE) характерно одно важное ограничение - они не допускают прямого подключения устройств к Интернету. Подключение к Интернету необходимо для дистанционного контроля и проверки истории операций, проводимых устройством [2]. В результате, некоторые из моделей умных замков оснащены внешними шлюзами для создания моста между замком с каналом Bluetooth и домашней сетью с каналом Wi-Fi. Некоторые из этих замков имеют другой тип беспроводной связи (например, Z-Wave) и соответствующий шлюз между умным замком и домашней сетью Wi-Fi. Вот примеры нескольких популярных смарт-замков и используемых в них типов беспроводной связи:

- August Smart Lock - интерфейс Bluetooth;

- August Smart Lock HomeKit Enabled - интерфейсы Bluetooth, Wi-Fi;

- August Smart Lock Pro + Connect - интерфейсы Bluetooth, Wi-Fi, Z-Wave;

- Nest X Yale Lock with Nest Connect - интерфейс Wi-Fi;

- Yale Assure Lock SL - интерфейс Z-Wave;

- Schlage Sense-интерфейс Bluetooth.

Умный замок всегда расположен внутри квартиры, и все коммуникации идут непосредственно между смартфоном и замком по Bluetooth или через Интернет (через шлюз и домашнюю сеть Wi-Fi), как показано на рис. 3. Большинство умных замков оснащено одним беспроводным каналом связи. Два или три канала могут быть только в системах с внешними шлюзами, как например в случае c August Smart Lock - базовая модель имеет только Bluetooth, a Wi-Fi и Z-Wave появляются в комплектах с внешними шлюзами.

В некоторых случаях дополнительные каналы связи, такие как Z-Wave, позволяют интегрировать умные замки в систему домашней автоматизации [3]. В этом случае

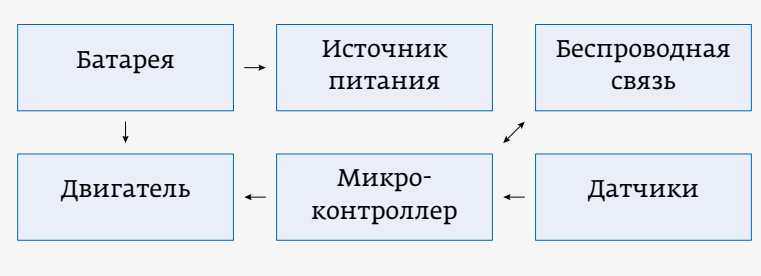

Рис. 2. Структурная схема умного замка

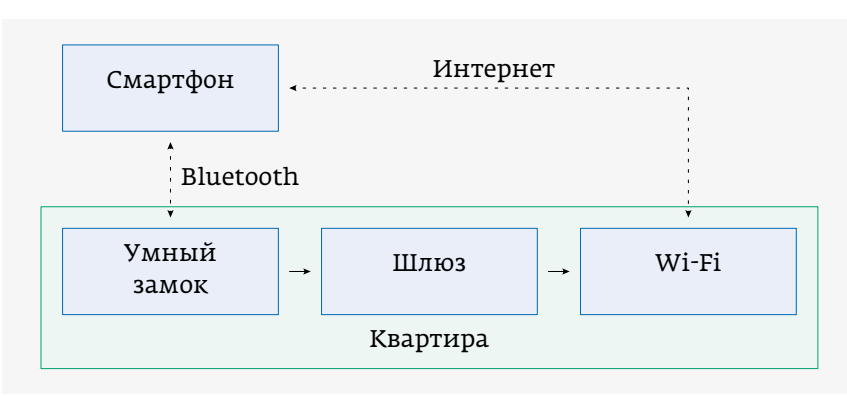

Рис. 3. Система связи между смартфоном и умным замком

умный замок является частью умного дома, но безопасность (взломостойкость) самого замка не будет превышать безопасность всей системы «Умный дом».

Подключение к Интернету повышает безопасность смарт-замков из-за наличия дополнительного канала контроля состояния. Умные замки с единственным каналом связи Bluetooth и без подключения к Интернету могут быть дистанционно "взломаны», при этом владелец квартиры узнает об этом только когда сам попадет в нее. Дополнительный канал связи позволяет непрерывно отслеживать состояние умного замка, а в случае его "взлома" и неожиданного открывания двери пользователь узнает об этом сразу же, как только это произойдет.

Существующие системы связи смарт-замков имеют один существенный недостаток - дополнительный канал связи расположен в одной квартире с умным замком, и злоумышленники могут просто отключить подачу электроэнергии в квартиру (отключить домашний Wi-Fi) или внешние кабели связи. После этого информация о неожиданном срабатывании умного замка пользователю не поступит.

Такого рода проблемы могут быть решены только путем изменения системы связи. Новая система должна иметь дополнительный канал связи между умным замком и шлюзом, при этом шлюз должен находиться вне квартиры.

\section{КОНСТРУКЦИЯ УМНОГО ЗАМКА С ДВУМЯ БЕСПРОВОДНЫМИ КАНАЛАМИ}

Умный замок с двумя беспроводными каналами связи был разработан, собран и успешно протестирован. Его механическая конструкция представлена на рис. 4, а электронная структура - на рис. 5. Замок имеет два беспроводных канала связи: 2,4 ГГц BLE; проприетарный протокол связи на частоте 433 МГц. Разработанный умный замок аналогичен другим существующим устройствам, за исключением второго канала связи в полосе частот 433 МГц.

Смартфон напрямую связывается с умным замком по BLE 2,4 ГГц. Этот канал поддерживается основным микроконтроллером СС2541. Микроконтроллер оптимизирован для работы с низким энергопотреблением и идеально 


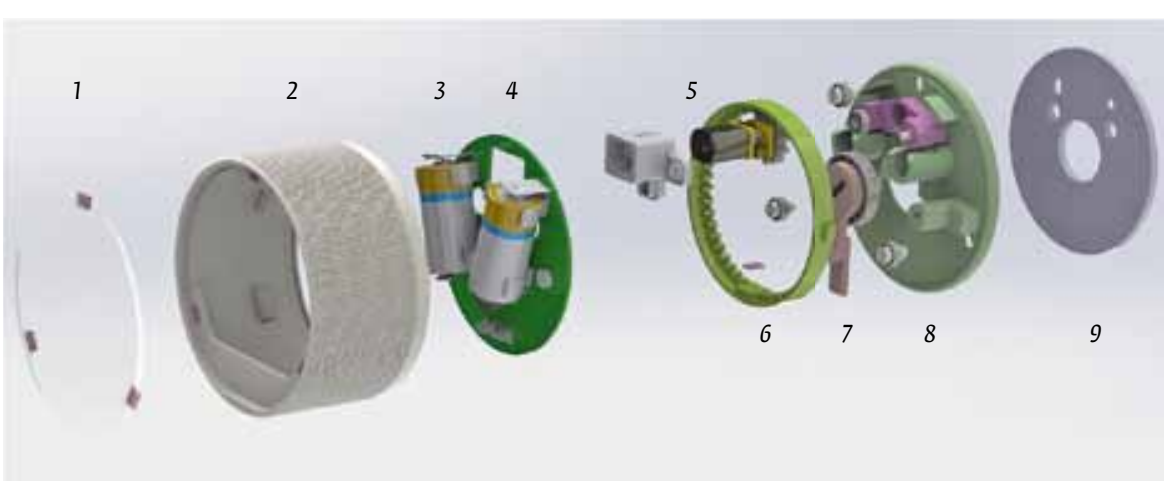

Рис. 4. Конструкция умного замка. 1 - крышка замка; 2 - корпус замка; 3 - батареи питания; 4 - плата электроники; 5 - двигатель; 6 - шестеренка; 7 - рычаг; 8 - основание замка; 9 - антивандальная шайба

соответствует требованиям к конструкции умных замков. Для полосы частот 433 МГц применяется малопотребляющий субгигагерцовый радиочастотный приемопередатчик АХ5243.

Канал связи 433 МГц используется для связи умного замка с пультом охраны, расположенным в выделенном помещении организации, которая охраняет квартиру пользователя (рис. 6). Пульт охраны подключен к серверу, который, в свою очередь, подключен к Интернету. Вся информация о состоянии умного замка и история операций доступны через Интернет с сервера.

Пользователь может напрямую управлять умным замком со смартфона по каналу BLE (находясь в нескольких метрах от двери) или через Интернет (из любой точки мира)

\section{РАСЧЕТ ВРЕМЕНИ АВТОНОМНОЙ РАБОТЫ УМНОГО ЗАМКА}

Второй канал связи повышает безопасность умного замка, но при этом увеличивает энергопотребление и уменьшает время автономной работы. Ожидаемое время работы

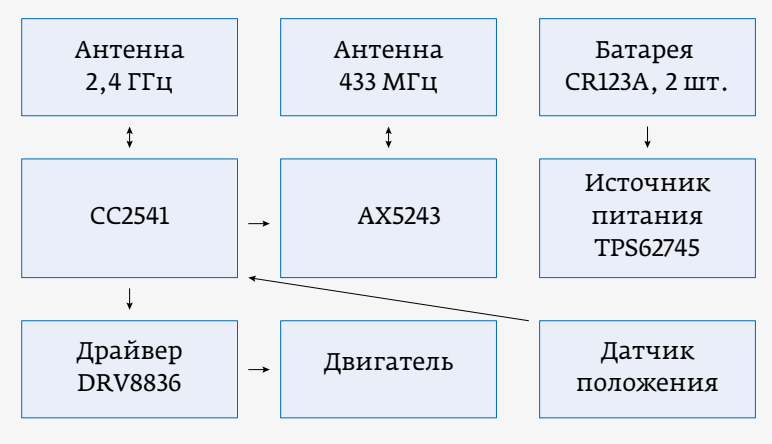

Рис. 5. Структурная схема умного замка с двумя каналами связи умного замка от одного комплекта батарей должно быть более одного года. Меньшее время эксплуатации может снизить интерес к продукту со стороны потенциальных пользователей после сравнения с конкурирующими устройствами .

Расчет потребления радиоканала 433 МГц основан на том, что передача сообщений производится каждые 15 с, при этом передается 9 байт данных. При скорости 100 кБит / с время работы трансивера для передачи (9 байт × 8 бит × 100000 бит/с) равно примерно 720 мкс, что составляет примерно 1/20800 от общего времени работы устройства $(0,00072$ с / 15 с).

Максимальный ток потребления трансивера АХ5243 в активном режиме передачи составляет 16 мА Средний ток потребления трансивера составляет: (16 мА/20 800) $\approx 0,8$ мКА.

Расчет потребления по каналу BLE основан на том, что максимальный ток потребления микроконтроллера СС2541 в режиме передачи составляет 18 мА. В этом случае модуль BLE каждые 2 с для поддержания канала связи отправляет запросы. Для 3,1-мс сеанса связи средний ток потребления будет равен: (18 мА × 3,1 мс / 2 с) 28 мкA.

Расчет среднего тока потребления электродвигателя основан на том, что он включается на 1 с в среднем 10 раз в сутки и потребляет во включенном состоянии около 50 мА: 50 мА × $10 \mathrm{c} /(24 \times 60 \times 60) \mathrm{c}=6$ мкA.

Общий средний ток потребления двух радиоканалов и электродвигателя: 0,8 мкA + 28 мкA + 6 мкA $\approx 35$ мкA.

Сравнение тока потребления канала 433 МГц (0,8 мкА) с общим током потребления всего устройства (35 мкА) показывает, что этот дополнительный канал влияет на время автономной работы умного замка незначительно.

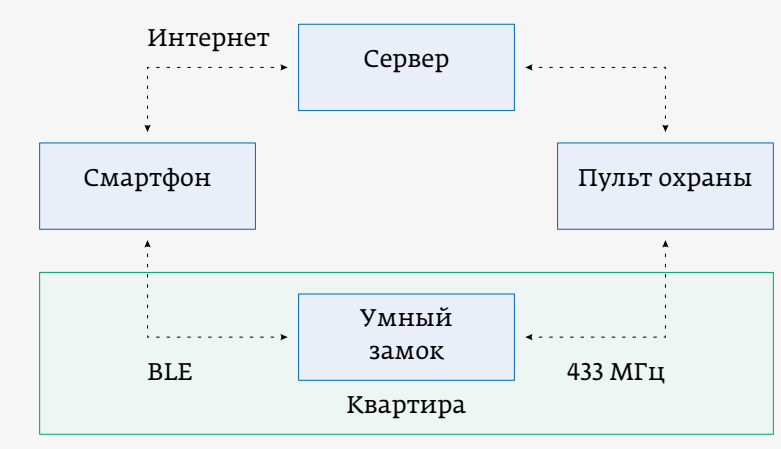

Рис. 6. Система связи между смартфоном и умным замком с двумя беспроводными каналами связи 
Электронные компоненты питаются от 3,3 В. Учитывая КПД преобразователя напряжения 95\%, средний ток потребления от батареи 6 В (две батареи по 3 В, соединенные последовательно) будет равен: $(35 \mathrm{MKA} \times 3,3 \mathrm{~B}) /(6 \mathrm{~B} \times 0,95) \approx 20 \mathrm{MKA}$.

Батареи имеют емкость не менее 1000 мА·ч. Теоретическое время работы на одном комплекте батарей составляет: 1000 мА·ч / 0,02 мА / 24 ч / 31 день $\approx 67$ месяцев (больше 5,5 лет).

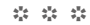

Таким образом, дополнительный канал связи в полосе частот 433 МГц практически не влияет на время автономной работы умного замка, но добавляет системе несколько важных преимуществ. Данный канал:

- использует нестандартный протокол связи, что значительно увеличивает сложность "взлома», поскольку в открытом доступе информация о протоколе отсутствует;

- соединяет умный замок с защищенным сервером, к которому со стороны потенциальных злоумышленников нет доступа;

- контролируется не только пользователем, но и охранной организацией, что практически исключает человеческий фактор при принятии решения в случае проникновения злоумышленника в охраняемое помещение.
Все вышеперечисленные факторы значительно повышают безопасность помещений с установленным умным замком предложенной конструкции, и пользователи будут доверять таким устройствам значительно больше, чем обычным умным замкам.

Работа выполнена в СПбгЭТУ "ЛЭТИ» в рамках реализации комплексного проекта по созданию высокотехнологичного производства, в соответствии с постановлением Правительства Российской Федерации от 9 апреля 2010 года № 218, договор № 03.G25.31.0256.

\section{ЛИТЕРАТУРА}

1. Hadis M.S., Palantei E., Ilham A. A., and Hendra A.

Design of smart lock system for doors with special features using bluetooth technology. In: 2018 International Conference on Information and Communications Technology (ICOIACT) (March 2018). PP. 396-400.

2. Pavelić M., Lončarić Z., Vuković M., and Kušek M. Internet of things cyber security: Smart door lock system. In: 2018 International Conference on Smart Systems and Technologies (SST) (Oct. 2018), PP. 227-232.

3. Wei C-C., Chen Y-M., Chang C-C., Yu C-H. The Implementation of smart electronic locking system based on Z-Wave and Internet. - IEEE International Conference on Systems, Man and Cybernetics (Oct. 2015). 2015. PP. 2015-2017.

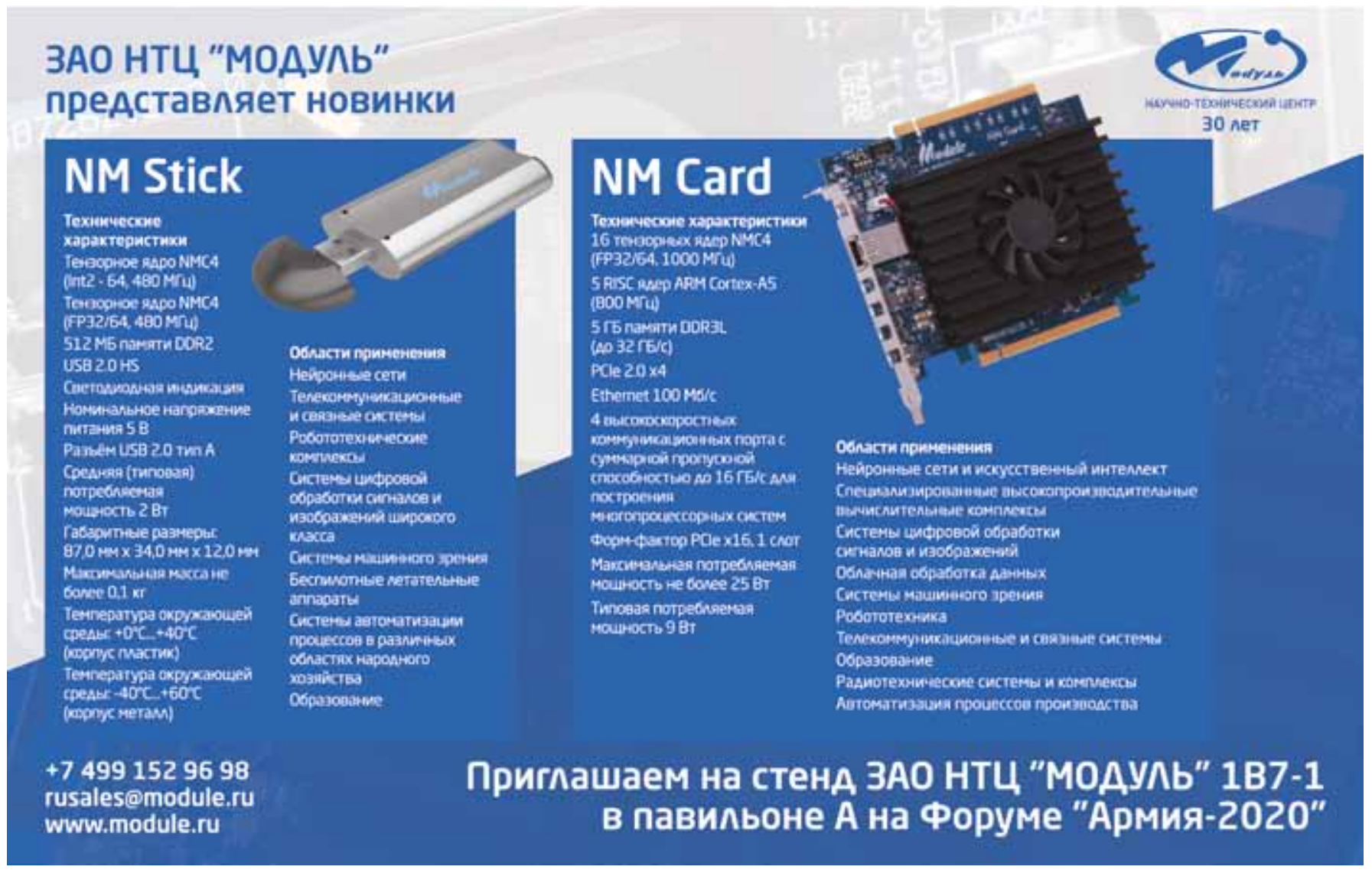

